\title{
Cultural Globalization and Music: African Artists in Transnational Networks
}

\author{
Nadia Kiwan and Ulrike Hanna Meinhof \\ Basingstoke: Palgrave Macmillan, 2011 \\ ISBN: $9780230221291(\mathrm{HB})$ \\ RRP: $\$ 90.00$ (USD)
}

\author{
Rachel Muehrer \\ York University, Canada \\ rachel.muehrer@gmail.com
}

Migrant musicians on the African continent have established intricate networks between Europe and home, often returning from abroad to re-energize in their local musical community while bringing back with them cultural cache. Nadia Kiwan and Ulrike Hannah Meinhof's study sets out to create a new model of these global music networks that span Europe and Africa. This model includes a host of interactions between the North and the South. As well as connections among translocal (within a nation) and transnational (beyond the nation) communities that are sustained through the movement of musicians, musical influence and resource sharing (such as money, equipment and promotion). This ethnographic work uses case studies of musicians from North Africa and Madagascar who have relocated to Europe in order to detail the intricacies and complexities of these networks. The book is divided into four parts: the introduction describes the author's methodology and migration model, Part 1 describes networks that exist in the South (North Africa and Morocco), Part 2 describes the relationships in Europe that have taken root to create musical communities among African migrant musicians and Part 3 describes mutually beneficial relationships between the North and the South. The authors also include an appendix of interviews in their original French and German.

In the introduction to their collection of case studies, Kiwan and Meinhof carefully situate their methodological and theoretical approach, explaining that their work considers "a wider set of interconnections than is usually the case in migration studies" (2011: 2). The glue that connects the networks is called a hub. There are four varieties: human hubs, which crucially link each part of the network, spatial hubs, the geographic points where musical networks converge, institutional hubs, local, national or global organizations that collaborate with musicians, and accidental hubs; often created by the researchers themselves who study these networks and at the same time extend them. Another key concept that is central to this model is transcultural capital, a concept introduced by Meinhof and Triandafyllidou (2006) that builds on Bourdieu's theory of cultural and symbolic capital. The authors define it as:

A heuristic concept to enable interpretation and analysis of resources typically associated with transnational migrants who retain substantive links between country of origin and country/ies of settlement and who activate the continuing interdependencies between 
them in various flows and cycles of migration, return and re-return (Kiwan and Meinhof 2011: 8).

These links are maintained by the "redirecting of artistic energy" (50) and the creation and support of live music performances. Transcultural capital is an important concept because migrant musicians are able to use it to build and maintain a career and musical network in their country of settlement by converting their cultural capital into economic capital.

Part one of the book includes a discussion of Madagascar and Morocco and the kinds of spaces, rural and urban, that a musician might traverse in her or his translocal networks as well as the opportunities afforded in each space. There is a major focus on how musicians utilize translocal capital and how they navigate the resources available throughout these translocal networks. The other focus of this section is the importance of metropolitan cities where musicians often use their resources and know-how to support other musicians, organize events and even influence the style of the transnational music scene. Of course the cities act as hubs themselves, since they act as host for cultural activities, musical facilities such as rehearsal sites, recording studios and performance venues. They also act as a link to international sites should artists wish to migrate in order to build international careers.

In the second section of the book, the authors discuss cities in Europe that are part of transnational musical networks, first explaining that their theoretical approach is to challenge top-down economic views of globalization by highlighting the agency of individuals and organizations and how they might influence "cultural processes of globalization" (2011: 88). The authors go on to stress that although African musicians based in Europe often have tremendous influence on the musical and cultural scene in the European metropolis, they do so without significant economic capital. Rather, "artists' 'extensive connectivity' to their countries of origin and their 'extensive global consciousness' (Robertson and White 2003: 6) mean that their presence in major European cities can be read as localized, concrete manifestations of cultural globalization and its associated networks and flows" (2011: 88). Part 2 concludes with a description of the networks that are built between major cities in Europe and more rural locales through "multi-sited individuals" (121) as well as those artists that return to their country of origin after residing in Europe, often to help strengthen the local cultural and musical scene.

Finally, Part 3 of the work is an examination of the contribution of mutual support systems between the North and the South in a postcolonial Africa. This section begins with a discussion of cultural institutions that have relationships with Morocco and Madagascar. Although these institutions exist to promote European culture, the authors argue that they provide African musicians with "translocal and transnational cultural space that allows artists to increase their networking capacity and thus to facilitate sustainable cultural development" (2011: 160). Kiwan and Meinhof also make sure to highlight the problematic nature of these relationships, questioning whether this 'mutual support' system actually works both ways. The authors also discuss the normally neglected role of civil society movements, including groups that are formed within ethnic groups of a diasporic community, European associations that support development projects in Africa, and European organizations that are based in Africa and utilise European resources. While the economic power differential of 'North to South' aid projects have often been ineffective because they have failed to involve local perspective, the authors argue that the recent participation of local artists in these initiatives "challenges stereotypes of givers and takers and creates a new relationship of mutuality" (2011: 191). This new dialogue is certainly a step in the right direction-an attempt to counteract the legacy of colonialism and international aid-but the idea of "mutual" support between North and South is still a dubious one. 
It is clear that Kiwan and Meinhof's extensive ethnographic study offers insight into the global network in which African musicians participate. By approaching their work as a study of individual migrant musicians and by examining the movements and reach of these individuals, they are able to illuminate the nuances of relationships between individuals, organizations, institutions and geographic space as well as the flow of cultural capital among them. The authors also managed to acknowledge the oftenoverlooked impact of their own work, and problematize the economic power relations between Europe and Africa while emphasizing the agency and savvy that musicians demonstrate through their handling of cultural capital.

\section{References}

Meinhof, Ulrike Hanna and Anna Triandafyllidou (Eds). 2006. Transcultural Europe:

Cultural Policy in a Changing Europe. Basingstoke: Palgrave Macmillan.

Robertson, Roland and Kathleen White (Eds). 2003. Globalization: Critical Concepts in Sociology, vol. 1. London and New York: Routledge. 